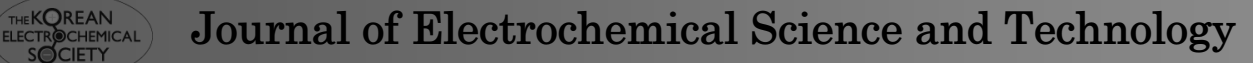

\title{
Catalytic Effects of Heteroatom-doped Graphene Nanosheets on the Performance of $\mathrm{Li}^{-} \mathrm{O}_{2}$ Batteries
}

\author{
Youngjoon Bae, Hee-Dae Lim, Young Soo Yun, and Kisuk Kang* \\ Department of Materials Science and Engineering, Seoul National University, 1 Gwanak-ro, Gwanak-gu, Seoul 151-742, \\ South Korea
}

\begin{abstract}
Graphene nanosheets (GNS), nitrogen-doped graphene nanosheets (N-GNS), and sulfur-doped graphene nanosheets (SGNS) were successfully synthesized, and their catalytic effects on the oxygen reduction reaction (ORR) in $\mathrm{Li}_{-} \mathrm{O}_{2}$ batteries were compared. The S-GNS electrode exhibited the highest ORR catalytic activity, resulting in enhanced discharge capacity and power capability. We attributed the enhanced ORR catalytic activity to the increased defect sites on graphene.
\end{abstract}

Keywords: $\mathrm{Li}^{-\mathrm{O}_{2}}$ batteries, graphene, doping, nanosheets, heteroatom

Received February 11, 2014 : Accepted February 26, 2014

\section{Introduction}

Li- $\mathrm{O}_{2}$ batteries have attracted attention because they can deliver the highest energy density (theoretical value of $\sim 3,500 \mathrm{Wh} \mathrm{kg}^{-1}$ ) among all types of batteries [1-5]. An unlimited source of oxygen makes $\mathrm{Li}^{-} \mathrm{O}_{2}$ technology attractive for next-generation batteries. $\mathrm{Li}$ ions $\left(\mathrm{Li}^{+}\right)$and oxygen $\left(\mathrm{O}_{2}\right)$ react on a cathode substrate, forming $\mathrm{Li}_{2} \mathrm{O}_{2}$ discharge products $\left(2 \mathrm{Li}^{+}+\mathrm{O}_{2}+2 \mathrm{e}^{-} \rightarrow \mathrm{Li}_{2} \mathrm{O}_{2}, 2.96 \mathrm{~V}\right)$ [3]. There are no heavy transition metals or crystal framework required to store $\mathrm{Li}$ ions, which leads to an extremely high energy density. On the other hand, a highly conductive substrate with a large surface area is useful for storing the non-conductive, solid-state discharge products. Thus, the choice of substrate material is a key factor that determines the electrochemical properties of $\mathrm{Li}-\mathrm{O}_{2}$ cells. Carbon-based materials have been commonly used as substrate materials because of their high surface area, porosity, and electrical conductivity.
Among the various carbon materials, graphene is one of the most attractive candidates because of its large surface area and superior electrical conductivity, which can compensate for the poor conductivity of the discharge products [6]. Furthermore, it was recently demonstrated that graphene exhibits oxygen reduction reaction (ORR) catalytic activity [7]; anchoring various dopants on graphene-based substrates can affect the catalytic properties of graphene [7-15].

In this study, nitrogen-doped graphene nanosheets (N-GNS) and sulfur-doped graphene nanosheets (SGNS) were prepared from graphene oxide (GO) by thermal treatments with nitrogen and sulfur dopants, and their electrochemical performances as cathode materials for $\mathrm{Li}-\mathrm{O}_{2}$ batteries were compared with that of bare graphene nanosheets (GNS). We found that the nitrogen and sulfur dopants enhanced the ORR catalytic activity of $\mathrm{Li}-\mathrm{O}_{2}$ batteries; this was attributed to the increased defect sites in heteroatom-doped GNS.

*Corresponding author. Tel.: +492518336725

E-mail address: stefano.passerini@uni-muenster.de

Open Access DOI: http://dx.doi.org/10.5229/JECST.2014.5.2.49

This is an Open Access article distributed under the terms of the Creative Commons Attribution Non-Commercial License (http://creativ ecommons.org/licenses/by-nc/3.0/) which permits unrestricted non-commercial use, distribution, and reproduction in any medium, provided the original work is properly cited. 


\section{Experimental}

GO was prepared from natural graphite (Sigma-Aldrich) using the modified Hummers method [16]. Aqueous GO suspensions were frozen in liquid nitrogen and then freeze-dried using a lyophilizer (LP3, Jouan, France) at $50^{\circ} \mathrm{C}$ and $0.045 \mathrm{mbar}$ for $72 \mathrm{~h}$. After lyophilization, low-density and loosely packed GO powders were obtained. The melamine monomer $(0.5 \mathrm{mg} /$ $\mathrm{mL}$ ) was added to the GO solution to dope GO with nitrogen and obtain N-GNS. The solution of melamine and graphene was frozen in liquid nitrogen and freezedried using a lyophilizer at $50^{\circ} \mathrm{C}$ and $0.045 \mathrm{mbar}$ for $72 \mathrm{~h}$. The lyophilized mixture was thermally treated at $600^{\circ} \mathrm{C}$ for $2 \mathrm{~h}$. The resultant product (N-GNS) was stored in a vacuum oven at $30^{\circ} \mathrm{C}$. S-GNS was prepared using elemental sulfur. Equal amounts $(100 \mathrm{mg})$ of the as-obtained lyophilized GO powder and elemental sulfur powder (Sigma-Aldrich, 99.98\%) were mixed in a mortar. The mixture was thermally treated in a tubular furnace at $600^{\circ} \mathrm{C}$ for $2 \mathrm{~h}$. The resultant product (S-GNS) was stored in a vacuum oven at $30^{\circ} \mathrm{C}$. Bare GNS was prepared by repeating the same procedure without the elemental sulfur powder.

The air electrode was composed of a mixture of the prepared graphene and binder (Kynar 2801) at a weight ratio of 80:20. The mixtures were dispersed in N-methyl2-pyrrolidone (NMP, Sigma-Aldrich, 99.5\%) and cast onto a Ni-mesh current collector. Lithium metal (3/8-inch diameter), one sheet of glass fiber separator (Whatman GF/D microfiber filter paper, $2.7-\mu \mathrm{m}$ pore size), and the prepared cathode were stacked in sequence in a Swagelok-type Li-air cell. The electrolyte was $1 \mathrm{M}$ lithium bis(trifluoromethane)sulfonamide (LiTFSI) in tetraethylene glycol dimethylether (TEGDME). All the cells were assembled in a glove box and operated in an oxygen atmosphere (770 Torr). Each cell was relaxed for $1 \mathrm{~h}$ in

a

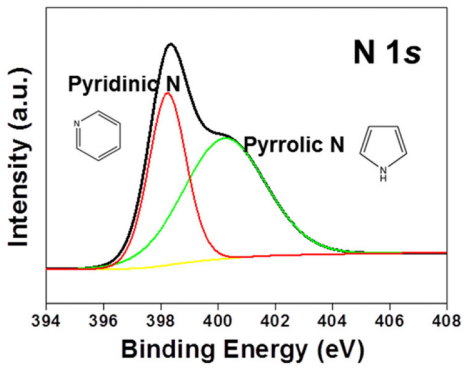

an oxygen atmosphere before testing to ensure cell stabilization. A potentio-galvanostat (WonA Tech, WBCS 3000 , Korea) was used to measure the electrochemical properties. X-ray photoelectron spectroscopy (XPS, PHI 5700 ESCA), field-emission scanning electron microscopy (FE-SEM, S-4300, Hitachi, Japan), and Raman spectroscopy (Horiba Jobin-Yvon, LabRam HR, France) were used for the analyses.

\section{Results and Discussion}

The morphologies of the synthesized GNS, N-GNS, and S-GNS were observed by SEM (Fig. 1a-c). All the samples had similar morphologies of a thin, curled structure. Energy-dispersive spectroscopy (EDS) mapping, corresponding to the SEM images of N-GNS and S-GNS (Fig. $1 \mathrm{~d}$ and e, respectively), demonstrated that the nitrogen and
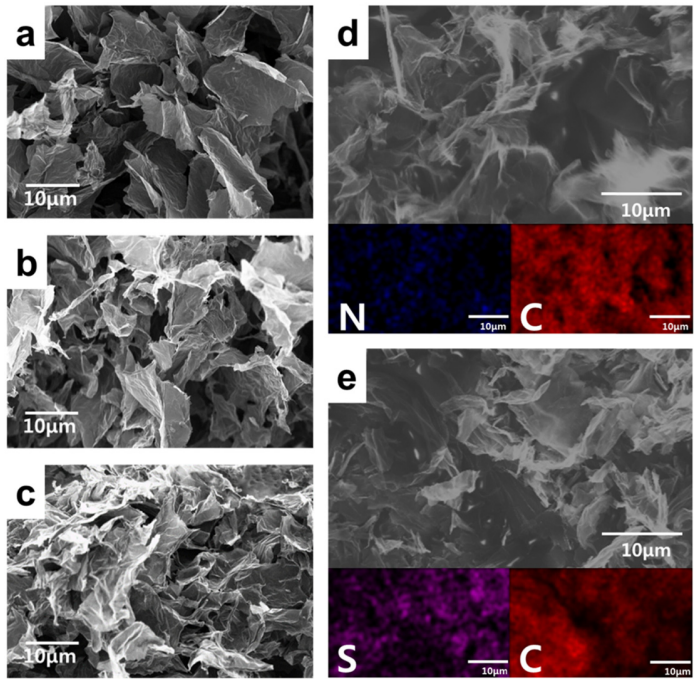

Figure 1. SEM images of (a) GNS, (b) N-GNS, and (c) SGNS, and EDS mapping of (d) N-GNS and (e) S-GNS.

b

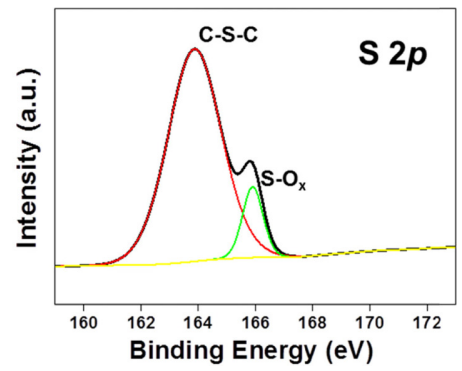

Figure 2. (a) XPS N $1 s$ spectra of N-GNS, and (b) XPS S $2 p$ spectra of S-GNS. 
sulfur were uniformly doped onto the surface of GNS.

The chemical configurations of nitrogen and sulfur were confirmed by XPS (Fig. 2). The XPS N $1 s$ spectra of N-GNS showed the two distinct peaks of pyridinic $\mathrm{N}(398.2 \mathrm{eV})$ and pyrrolic $\mathrm{N}(400.3 \mathrm{eV})$, corresponding to six- and five-membered rings at the edge of a graphene sheet (Fig. 2a). The presence of these chemical species indicates the broken symmetry of the infinite carbon honeycomb lattice. In the XPS S $2 p$ spectra of S-GNS, the C-S-C peak $(163.8 \mathrm{eV})$ and $\mathrm{C}^{-} \mathrm{SO}_{\mathrm{x}}$ - peak $(165.9 \mathrm{eV})$ were dominant (Fig. 2b). The covalent $\mathrm{C}-\mathrm{S}-\mathrm{C}$ bonding is attributable to an $\mathrm{S}$ adatom on a $\mathrm{C}-\mathrm{C}$ bond, an $\mathrm{S}$ adatom on a monovacancy, or an $\mathrm{S}_{2}$ dimer on a divacancy.

The electrochemical performances of GNS, N-GNS, and S-GNS at current densities of 0.1 and $0.2 \mathrm{~mA} \mathrm{~cm}^{-2}$ were investigated (Fig. 3). While the GNS electrode delivered a discharge capacity of $370 \mathrm{mAh} \mathrm{g}^{-1}$, the discharge capacities of N-GNS and S-GNS increased to 1280 and $1980 \mathrm{mAh} \mathrm{g}^{-1}$ after nitrogen and sulfur doping at a current density of $0.1 \mathrm{~mA} \mathrm{~cm}^{-2}$. Even at the higher current rate, the discharge capacities of heteroatom-doped GNS electrodes were greater than that of the bare GNS. Based on the discharge capacity results at different current rates, the rate capability of S-GNS was the highest among the three graphene-based electrodes. It has been reported that N-GNS exhibits ORR catalytic activity due to the partial positive charge sites that result from the difference in electronegativity between nitrogen and carbon, which increases oxygen adsorption (electronegativity of nitrogen: 3.04; carbon:2.55) $[14,15]$. In addition, the increased defect sites could further enhance the ORR activity [17]. Therefore, the initial discharge capacity of N-GNS was higher than that of bare GNS (Fig. 3). In the case of S-GNS, although the difference in electronegativity between sulfur and carbon is much lower $(\sim 0.03)$ than that between nitro-

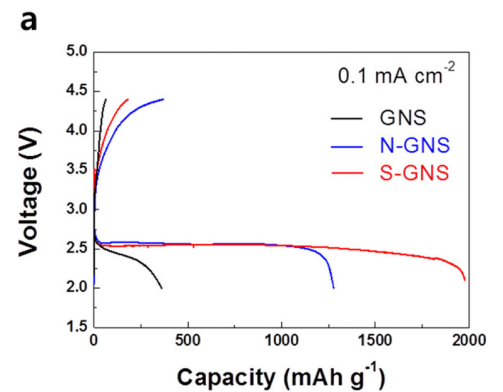

gen and carbon, the initial discharge capacity and rate capability of S-GNS were superior to those of N-GNS. This implies that factors other than electronegativity dominate the ORR activity; we investigated other factors using Raman analysis.

The Raman spectrum of GNS exhibited $D$ and $G$ peaks at $\sim 1360.6$ and $\sim 1599.8 \mathrm{~cm}^{-1}$, respectively (Fig. 4). The presence of the $D$ peak indicates the formation of defect sites having a broken symmetry of the infinite carbon honeycomb lattice. The $G$ peak originates from the doubly degenerate $\mathrm{E}_{2 \mathrm{~g}}$ phonon at the Brillouin zone center. The $D$ and $G$ peaks of GNS were shifted slightly to lower wavenumbers after doping. The Raman spectra of N-GNS and S-GNS exhibited $D$ peaks at $\sim 1355.6$ and $1353.2 \mathrm{~cm}^{-1}$, respectively, and $G$ peaks at $\sim 1593.8$ and $1589.4 \mathrm{~cm}^{-1}$, respectively. The shift of the $D$ and $G$ peaks indicates successful electron doping of GNS and supports the doping of heteroatoms [18]. Also, the D/G ratios of N-GNS and SGNS were 1.00 and 1.15 , respectively. Both ratios were larger than that of GNS (0.88), indicating an increase in defect sites after doping. S-GNS had more defect sites than N-GNS, which might be due to the

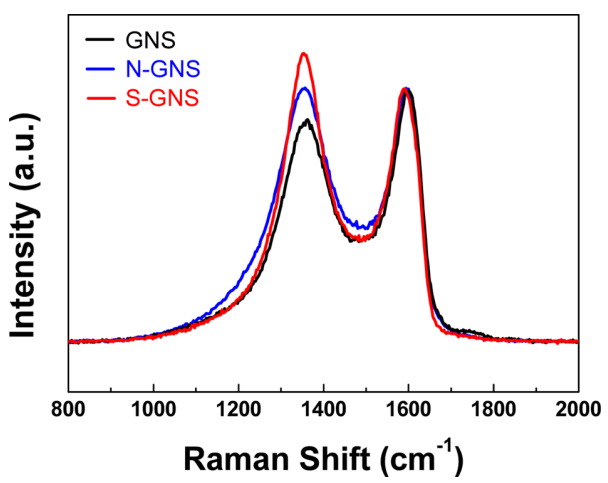

Figure 4. Raman spectra of GNS, N-GNS, and S-GNS.

b

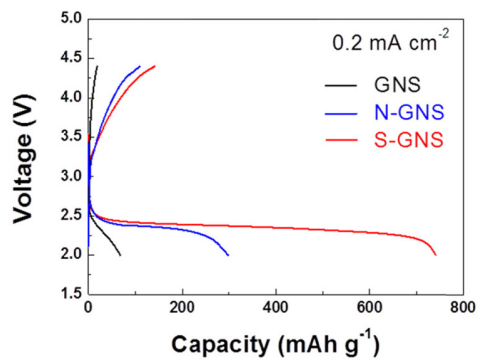

Figure 3. Discharge-charge curves of GNS, N-GNS, and S-GNS at current densities of (a) $0.1 \mathrm{~mA} \mathrm{~cm}^{-2}$ and (b) $0.2 \mathrm{~mA} \mathrm{~cm}^{-2}$. 
larger radius of a sulfur atom $(100 \mathrm{pm})$ compared to nitrogen $(65 \mathrm{pm})$ and carbon $(70 \mathrm{pm})$ [19].

In previous reports, theoretical calculations using density functional theory (DFT) showed that the nucleation and growth of discharge products are most likely to occur around the defect sites [20]. The defect sites in S-GNS are thought to provide numerous nucleation sites for the formation of $\mathrm{Li}_{2} \mathrm{O}_{2}$, resulting in a high discharge capacity. S-GNS exhibited a higher discharge capacity than N-GNS due to a greater number of defect sites, even though S-GNS had a negligible difference in electronegativity between nitrogen and carbon. Additionally, S-GNS had the highest rate capability among the three samples because the numerous nucleation sites that resulted from increased defect sites facilitated rapid growth of the discharge products.

\section{Conclusion}

N-GNS and S-GNS were prepared by thermal treatment with melamine and elemental sulfur, respectively. N-GNS and S-GNS had increased defect sites, which resulted in enhanced ORR catalytic activity compared to GNS. N-GNS and S-GNS showed discharge capacities of 1280 and $1980 \mathrm{mAh} \mathrm{g}^{-1}$, respectively, which were much higher than that of GNS $\left(370 \mathrm{mAh} \mathrm{g}^{-1}\right)$. In addition, N-GNS and S-GNS showed enhanced rate performances compared to GNS; this was attributed to additional defect sites that promoted nucleation of the discharge products.

\section{References}

[1] K. M. Abraham and Z. Jiang, J. Electrochem. Soc., 143, 1 (1996).

[2] P. G. Bruce, S. A. Freunberger, L. J. Hardwick and J.-M.
Tarascon, Nat. Mater., 11, 19 (2012).

[3] R. Black, S. H. Oh, J.-H. Lee, T. Yim, B. Adams and L. F. Nazar, J. Am. Chem. Soc., 134, 2902 (2012).

[4] Z. Peng, S. A. Freunberger, L. J. Hardwick, Y. Chen, V. Giordani, F. Bardé, P. Novák, D. Graham, J.-M. Tarascon and P. G. Bruce, Angew. Chem., 123, 6475 (2011).

[5] Y.-C. Lu, H. A. Gasteiger and Y. Shao-Horn, J. Am. Chem. Soc., 133, 19048 (2011).

[6] M. D. Stoller, S. Park, Y. Zhu, J. An and R. S. Ruoff, Nano Lett., 8 (5), 3498 (2008).

[7] B. Sun, B. Wang, D. Su, L. Xiao, H. Ahn and G. Wang, Carbon, 50, 727 (2012).

[8] L. Qu, Y. Liu, J.-B. Baek and L. Dai, ACS Nano, 4 (3), 1321 (2010).

[9] D. Geng, Y. Chen, Y. Chen, Y. Li, R. Li, X. Sun, S. Ye and S. Knights, Energy Environ. Sci., 4, 760, (2011).

[10] Y. Shao, S. Zhang, M. H. Engelhard, G. Li, G. Shao, Y. Wang, J. Liu, I. A. Aksay and Y. Lin, J. Mater. Chem., 20, 7491 (2010).

[11] L. Tang, Y. Wang, Y. Li, H. Feng, J. Lu and J. Li, $A d v$. Funct. Mater., 19, 2782 (2009).

[12] K. R. Lee, K. U. Lee, J. W. Lee, B. T. Ahn and S. I. Woo, Electrochem. Commun., 12, 1052 (2010).

[13] G. Wu, N. H. Mack, W. Gao, S. Ma, R. Zhong, J. Han, J. K. Baldwin and P. Zelenay, ACS Nano, 6, 9764 (2012).

[14] Y. Wang, Y. Shao, D. W. Matson, J. Li and Y. Lin, $A C S$ Nano, 4, 1790 (2010).

[15] L. Yang, S. Jiang, Y. Zhao, L. Zhu, S. Chen, X. Wang, Q. Wu, J. Ma, Y. Ma and Z. Hu, Angew. Chem. Int. Ed., 50, 7132 (2011).

[16] W. S. Hummers and R. E. Offeman, J. Am. Chem. Soc., 80, 1339 (1958).

[17] Y. Li, J. Wang, X. Li, D. Geng, M. N. Banis, R. Li and X. Sun, Electrochem. Commun., 18, 12 (2012).

[18] A. M. Rao, P. C. Eklund, Shunji Bandow, A. Thess and R. E. Smalley, Nature, 388, 257 (1997).

[19] S.-A. Wohlgemuth, R. J. White, M.-G. Willinger, M.-M. Titirici and M. Antonietti, Green Chem., 14, 1515 (2012).

[20] J. Xiao, D. Mei, X. Li, W. Xu, D. Wang, G. Graff, W. Bennett, Z. Nie, L. Saraf, I. Aksay, J. Liu and J.-G. Zhang, Nano Lett., 11, 5071 (2011). 